Cadernos de

ESTUDOS LINGǘĺsTICOS - (57.2), Campinas, Jul./Dez. 2015

\title{
DISCURSO NA FANPAGE "SÓ GORDINHAS" SOBRE A PERSONAGEM PERSÉFONE DA NOVELA AMOR À VIDA
}

\author{
ANE CRISTINA THUROW \\ Universidade Católica de Pelotas \\ CLÓRIS MARIA FREIRE DOROW \\ Instituto Federal de Educação, Ciência e Tecnologia Sul-rio-grandense - \\ Campus Pelotas
}

\begin{abstract}
RESUMO: O uso crescente da Internet, principalmente das redes sociais, tem influenciado cada vez mais a vida das pessoas. Um site de rede social muito utilizado é o Facebook, que permite o acesso e a criação de fanpages (comunidades). Partindo do entendimento de que o discurso da fanpage está inscrito numa formação discursiva de "aceitação do corpo", o trabalho tem como objetivo geral refletir sobre os possíveis efeitos de sentido gerados nas práticas discursivas produzidas no espaço enunciativo da fanpage "Só Gordinhas" a respeito da personagem Perséfone apresentada na novela "Amor à Vida" da Rede Globo. Para tanto, o procedimento metodológico desenvolvido constitui-se na análise interpretativa dos enunciados produzidos na fanpage. E assim, com base nos pressupostos da Análise de Discurso pecheuxtiana, consideram-se alguns conceitos primordiais para a interpretação desse corpus, dentre os quais: discurso como "efeito de sentido entre locutores" (PÊCHEUX, 2009); sujeito discursivo, que ocupa um lugar social, atravessado pelo inconsciente e interpelado pela ideologia; formação discursiva, representando o lugar de constituição do sentido e da identificação do sujeito; e silêncio, que possibilita pensar na incompletude constitutiva de todo discurso. Com este trabalho, espera-se evidenciar as diferentes posições-sujeito que se entrecruzam numa dada formação discursiva, constituídas por discursos acerca da popularização da imagem da personagem citada, que pode ser analisada como uma figura que emana simpatia e/ou preconceito imposto pela mídia.
\end{abstract}

Palavras-chave: Facebook, formação discursiva, silêncio.

RESUMEN: El creciente uso de la Internet, especialmente de las redes sociales, ha influido cada vez más la vida de las personas. Un sitio de rede social ampliamente utilizado es el Facebook, que permite el acceso y la creación de fanpages (comunidades). Con base en el entendimiento de que o discurso de la fanpage se inscribe en una formación discursiva de "la aceptación del cuerpo", el trabajo tiene como principal objetivo reflexionar sobre los posibles efectos de sentido generados en las prácticas discursivas que se producen en el espacio de enunciación de la fanpage "Só Gordinhas" a respecto del carácter Perséfone presentados en la telenovela "Amor à Vida" del Rede Globo. Por lo tanto, el enfoque metodológico constituye el análisis interpretativo de los enunciados producidos en la fanpage. Y así, sobre la base de los supuestos del Análisis de Discurso pecheuxtiana, se consideran algunos conceptos fundamentales para la interpretación de este corpus, entre los cuales: discurso como "efecto de sentido entre charlatanes" (PÊCHEUX, 2009); sujeto discursivo, que ocupa un lugar social, cruzado por el inconsciente y detenido por la ideología; formación discursiva, que representa el lugar de constitución del significado e identificación del sujeto; y silencio que permite pensar en la 
incompletitud constitutiva de todo discurso. Con este trabajo se espera mostrar diferentes posiciones de sujeto que se cruzan en una formación discursiva determinada, que consiste en discursos sobre la popularización de la imagen de dicho personaje, que puede ser analizada como una figura que irradia simpatía y / o prejuicio impuesto por los medios de comunicación.

Palabras-llave: Facebook, formación discursiva, silencio.

\section{INTRODUÇÃO}

A mídia eletrônica está presente na vida das pessoas, seja através das emissoras de rádio e televisão ou pela Internet nos sites de redes sociais. As telenovelas têm uma temática social a qual envolve uma reflexão crítica da realidade, possibilitando análises individualizadas dos telespectadores que podem utilizar as redes sociais para discussão. O discurso analisado, nesse trabalho, baseia-se nos comentários referentes ao papel da personagem Perséfone da novela "Amor à Vida" exibida em 2013 pela emissora da Rede Globo, representada pela atriz Fabiana Carla. Empiricamente, a personagem representa uma mulher acima do peso, de 31 anos, virgem e bem sucedida profissionalmente.

Neste contexto, o tema das discussões dos telespectadores é norteado pela constituição da personagem pelo autor Walcyr Carrasco. A questão debatida versa sobre a personagem que representa uma mulher gorda, muito simpática, bem sucedida, com muitos amigos, mas que sofre uma rejeição pelo mundo masculino e não consegue perder a virgindade. As discussões giram em torno do tema de por que ela precisava ser gorda e também ser virgem. Aqui, o problema de excesso de peso, que é um tema atual, entra em cena, primeiramente por estar atrelado a pontos como a saúde individual, ao preconceito sofrido pelo obeso e, também, pela visão do estereótipo de beleza ditado pela mídia.

Nesse trabalho, busca-se analisar as discussões apresentadas na fanpage intitulada "Só Gordinhas", em que um dos tópicos é a visão da mulher gorda apresentada na novela "Amor à Vida" da Rede Globo presente no site de rede social do Facebook. Os comentários dos seguidores da fanpage foram verificados para a constituição da formação discursiva (FD) de "aceitação do corpo" que configura o discurso e a posição dominante desses sujeitos. Esse sujeito, ocupando um lugar social, é atravessado pelo inconsciente e interpelado pela ideologia. Assim, os pressupostos da Análise de Discurso pecheuxtiana possibilitaram um estudo sobre esse sujeito, constituído na e pela linguagem com um discurso de defesa da aceitação da aparência que possuem. Com isso, os enunciados produzidos sobre a personagem da novela foram analisados de modo a perceber as diferentes posiçõessujeito no interior da FD e os efeitos de sentido gerados por esse discurso.

1 Disponível em: <http://tvg.globo.com/novelas/amor-a-vida/personagem/persefone-fortino. html\#perfil/> Acesso em: 25 out. 2013.

${ }^{2}$ Disponível em: $<$ http://tvg.globo.com/novelas/amor-a-vida/index.html/> Acesso em: 25 out. 2013.

${ }^{3}$ Disponível em: $<$ https://www.facebook.com/SoGordinhas?fref=ts/> Acesso em: 25 out. 2013. 
Desta forma, tem-se como objetivo geral refletir sobre os possíveis significados gerados nas práticas discursivas produzidas no espaço enunciativo da fanpage "Só Gordinhas" a respeito da personagem Perséfone apresentada na novela "Amor à Vida" da Rede Globo. Partindo do entendimento de que este discurso está inscrito numa formação discursiva de "aceitação do corpo", o trabalho tem como objetivos específicos: i) analisar os enunciados produzidos no espaço enunciativo da fanpage sobre a imagem construída da personagem; ii) identificar os diferentes efeitos de sentido produzidos pelo tópico inicial da discussão e pelos comentários; iii) verificar, através da materialidade discursiva, as diferentes posições-sujeito que se inscrevem no interior dessa FD e como as mesmas se relacionam com a forma-sujeito; e iv) investigar, por meio do uso de reticências, os efeitos de sentido deixados pelo não uso de palavras.

\section{ANÁLISE DE DISCURSO}

O desenvolvimento do trabalho parte dos pressupostos teóricos da Análise de Discurso pecheuxtiana, baseando-se nos conceitos de discurso, sujeito, formação discursiva e silêncio, elementos essenciais para a análise do corpus. Com esse referencial, configura-se a possibilidade de análise interpretativa do discurso, apresentado em um site de rede social. Além disso, a questão do corpo na mídia é um assunto a ser observado, pois há um estereótipo valorizado como um modelo para as mulheres, como ser magra, alta, loira etc. Ainda, a postura na mídia eletrônica dos participantes da fanpage é o que possibilita perceber como se dão as relações intersubjetivas num determinado meio virtual. Para a análise dos discursos apresentados pelos sujeitos neste espaço virtual, a fundamentação teórica possibilitará uma interpretação possível.

A Análise de Discurso pecheuxtiana (AD), estruturada por Michel Pêcheux, constitui-se na relação entre três áreas do conhecimento - o materialismo histórico, a Linguística e a teoria do discurso - atravessada pela teoria da subjetividade (de natureza psicanalítica) (PÊCHEUX, 2014). Dessa relação surge uma disciplina de entremeio que tem como objeto de estudo o discurso.

$\mathrm{Na}$ teoria, há uma relação constitutiva da língua com a exterioridade. Isso possibilita analisar os enunciados na sua trama de sentidos, historicamente construídos em determinadas condições de produção, conjuntamente com a estrutura linguística, que funciona como materialização do discurso. Nesse contexto, ressalta-se que o objetivo da $\mathrm{AD}$ é explicar como o discurso, na sua materialidade discursiva, produz sentido.

O discurso produzirá sentidos na relação com discursos anteriores, por isso os sentidos das palavras não são fixos, estão em constante movimentação, sofrendo transformações sociais e políticas que constituem o sujeito. Segundo Orlandi (2012a), os discursos "não se originam em nós", pois eles "já estão em processo e nós é que entramos nesse processo" (idem, p. 35). Assim, os sentidos são produzidos em relação aos lugares enunciativos ocupados pelos sujeitos na prática discursiva, sendo que "todo discurso se delineia na relação com outros: 
dizeres presentes e dizeres que se alojam na memória" (idem, p. 44). Por isso, "não há discurso fechado em si mesmo, mas um processo discursivo do qual se pode recortar e analisar estados diferentes" (idem, p. 62).

Partindo disso, verifica-se que os diferentes discursos constituem o sujeito, seu grupo social e, principalmente, o seu dizer. Esse dizer produz um sentido que é determinado pelas formações discursivas que interpelaram esse sujeito. Orlandi (2012c) aborda que uma mesma palavra pode produzir diferentes sentidos de acordo com o lugar socioideológico daqueles que a empregam. E, desta forma, a ideologia se torna "a condição para a constituição do sujeito e dos sentidos" (ORLANDI, 2012a, p. 46), materializando-se e fazendo parte da linguagem. Logo, o indivíduo é interpelado em sujeito pela ideologia para que se produza o dizer (PÊCHEUX, 2009).

Segundo Pêcheux (2009, p. 146), “as palavras, expressões, proposições, etc., mudam de sentido segundo as posições sustentadas por aqueles que as empregam", o que significa que o sentido das palavras é dado em referência às formações ideológicas desses sujeitos. É importante ressaltar que cada formação ideológica constitui uma ou mais FDs, sendo que a FD é a materialização das formações ideológicas.

Na concepção da $\mathrm{AD}$, a ideologia constitui papel fundamental, visto que une o linguístico e o sócio-histórico. Nessa conjuntura, a linguagem é heterogênea em sua constituição, entendida como ação, transformação e representação simbólica das práticas discursivas nas suas implicações, nos seus conflitos, no seu reconhecimento e nas suas relações de poder. Desta forma, a linguagem possui uma relação com a exterioridade, sendo percebida nas condições de produção do discurso. Estas condições incluem os sujeitos e a situação, pois os efeitos de sentido encontram-se no discurso.

Por isso, diz-se que o discurso é "efeito de sentido" entre interlocutores (PÊCHEUX, 2009), visto que é atravessado pela ideologia e pela história. Ele é a palavra em curso, em movimento, é a fala produzindo sentidos, atravessado pelo inconsciente. Além disso, expõe Pêcheux (2009, p. 147) que as "palavras, expressões, proposições, etc., recebem seu sentido da formação discursiva na qual são produzidas". Dessa forma,

(...) “os indivíduos são interpelados em sujeitos falantes (em sujeitos de seu discurso) pelas formações discursivas que representam 'na linguagem' as formações ideológicas que lhes são correspondentes." Especificamos também que "a interpelação do indivíduo em sujeito de seu discurso se realiza pela identificação (do sujeito) com a formação discursiva que o domina". (idem, p. 198)

O sujeito, por estar inserido em um determinado lugar e tempo, é marcado pelo mecanismo ideológico, que naturaliza alguns sentidos e faz parecer claro que se fale de um modo e não de outro. Com isso, produz-se um sujeito descentrado que tem a ilusão de ser fonte e origem do seu discurso. $\mathrm{Na}$ sua constituição, o sujeito acredita ser livre e individual, mas ele é social e interpelado pela ideologia. O dizer do sujeito é determinado sempre por outros dizeres, ou seja, seu discurso se estabelece pelo interdiscurso, pela memória do dizer. Assim, 
Cadernos de ESTUDOS LINGḯlsTicos (57.2) - Jul./Dez. 2015

o sujeito não é fonte absoluta do significado, do sentido, não é a origem, pois ele é resultante da interação da relação com o social e o ideológico, mostrando seu caráter heterogêneo. Essa reflexão relaciona-se aos esquecimentos que são necessários para que o sujeito continue a produzir seu discurso acreditando ser o centro, a fonte do sentido constituído (PÊCHEUX, 2009).

De acordo com a AD, o sujeito é essencialmente ideológico e histórico, por estar inserido num tempo e lugar socialmente situados, formando seu posicionamento discursivo em relação ao discurso do outro. Nessa relação entre o linguístico e o social, a enunciação passa a ser um fator relevante para a interpretação e a constituição dos sentidos, visto que o sujeito e o sentido se constituem mutuamente.

Para se constituir e produzir sentidos, o sujeito precisa se submeter à língua e à história (ORLANDI, 2012c). A língua, por ser heterogênea e opaca, é passível de falhas, deslizes e equívocos (PÊCHEUX, 2008). Essas possibilidades da língua remetem à construção do sentido que não está interligado à palavra. $\mathrm{O}$ sentido é dado pelo sujeito que "é constituído por gestos de interpretação que concernem sua posição" (idem, p. 22) e é "o gesto de interpretação que realiza essa relação do sujeito com a língua, com a história, com os sentidos" (idem, p. 47).

É importante abordar que todo discurso produz sentidos a partir de outros sentidos já cristalizados na memória discursiva, legitimados na sociedade e recuperados pela historicidade. Sob esse aspecto, a produção dos sentidos acontece porque eles já estão lá, por já terem significado em algum momento, são os "já-ditos" (ORLANDI, 2012a).

Para Pêcheux (2009), não há discurso sem sujeito e não há sujeito sem ideologia: o indivíduo é interpelado em sujeito pela ideologia e é assim que a língua faz sentido. Por isso, a ideologia e inconsciente estão materialmente ligados. Desta forma, "um dizer tem relação com outros dizeres imaginados, realizados e possíveis" (ORLANDI, 2012a, p. 39). Diz-se que a incompletude é a condição da linguagem, isso porque nem os sujeitos, nem os sentidos e nem o discurso, já estão prontos e acabados. O que vai ao encontro da questão do sentido das palavras não serem fixos, nem predeterminados por estruturas e também não serem qualquer um, pois existe uma determinação histórica nessa relação de entremeio, em que os sentidos dependem de relações constituídas nas/ pelas FDs.

Com isso, o discurso é uma prática social repleta de significados e que só tomam forma e se constroem em relação a um contexto sócio-histórico e cultural, que envolve relações de poder e de ideologia. Foucault (1973) define o discurso como um conjunto de enunciados regulados numa mesma FD. As FDs são que explicam (pelas determinações ideológicas, pelos saberes e valores aceitos institucionalmente e socialmente adquiridos) o comportamento e as atitudes dessas pessoas no seu cotidiano.

Desta forma, um discurso resulta da combinação de diferentes discursos. Para compreender a $\mathrm{AD}$ e proceder à análise do discurso, é necessário compreender a noção de FD para Pêcheux (2009). O autor, ao se reportar a 
Foucault, argumenta que "uma FD não é um espaço estruturalmente fechado, pois é "invadido" por elementos que vêm de outro lugar (isto é, de outras FDs) que se repetem nela, fornecendo-lhe suas evidências discursivas fundamentais." (PÊCHEUX, 2014, p. 310). Para o autor,

chamaremos, então, formação discursiva aquilo que, numa formação ideológica dada, isto é, a partir de uma posição dada numa conjuntura dada, determinada pelo estado da luta de classes, determina o que pode e deve ser dito (articulado sob a forma de uma arenga, de um sermão, de um panfleto, de uma exposição, de um programa etc.). (PÊCHEUX, 2009, p. 147)

Através dessas palavras, aborda-se que uma formação ideológica é sempre constituída por diferentes FDs. Desta forma, um mesmo tema, ao ser posto em evidência, é objeto de conflitos, de tensão, devido às diferentes posições discursivas ocupadas que se opõem e se contestam. Assim, uma FD faz referência ao que se pode dizer em determinada época e em certo espaço social, a qual tem lugar sua realização, a partir de condições de produção específicas, historicamente definidas. Segundo Orlandi

(...) As formações discursivas, por sua vez, representam no discurso as formações ideológicas. Desse modo, os sentidos sempre são determinados ideologicamente. Não há sentido que não o seja. Tudo que dizemos tem, pois, um traço ideológico em relação a outros traços ideológicos. E isto não está na essência das palavras, mas na discursividade, isto é, na maneira como, no discurso, a ideologia produz seus efeitos, materializando-se nele. (ORLANDI, 2012a, p. 43)

Neste contexto, reitera-se que a FD é um espaço de natureza heterogênea. Em um discurso, o que o sujeito fala advém de uma FD e assim, tem um significado legado pela mesma e não um significado qualquer, isto porque as palavras de um discurso possuem significados próprios e derivam da FD da qual pertencem. Qualquer discurso proferido faz parte de uma dada FD que reflete a ideologia que subjaz à linguagem. Para Courtine (2009, p. 73, grifo do autor), "as FD são componentes interligados das FI" e também, "é no interior de uma FD que se realiza o 'assujeitamento' do sujeito (ideológico) do discurso".

Para Pêcheux (2009), uma FD comporta uma forma-sujeito historicamente determinada que regula, constitui e organiza o dizer das diferentes posiçõessujeito que nela convivem. E do mesmo modo, Orlandi expõe que "uma palavra, uma expressão se constitui pela sua inserção em uma formação discursiva e não outra" (2010, p. 17). E nesse contexto enunciativo, a historicidade é evidenciada na forma-sujeito que corresponde ao processo de socialização do indivíduo.

Essa forma-sujeito histórica é resultante da interpelação do indivíduo em sujeito pela ideologia. E nela aparece a contradição do sujeito moderno que é, "ao mesmo tempo livre e submisso, determinado pela exterioridade e determinador do que diz" e, por isso, "assujeitado" pela ideologia e pelo inconsciente (ORLANDI, 2010, p. 20). E esse sujeito social manifesta sua posição-sujeito projetada no discurso. E essas diferentes posições-sujeito, encontradas no discurso, se dão no jogo das formações imaginárias que podem ser relacionadas com "a imagem que o sujeito faz dele mesmo, a imagem que ele faz de seu interlocutor, a imagem que ele faz do objeto do discurso" (idem, p. 15). 
Na perspectiva discursiva, o que interessa é a forma como se organiza o discurso em sua materialidade linguística. Assim, o sentido sempre pode ser outro e o sujeito não tem controle daquilo que está dizendo. Como aborda Orlandi (2012b), quando uma palavra significa é porque a sua interpretação deriva de um discurso que a sustenta, que a mune de realidade significativa. É na compreensão do que é texto que podemos entender a relação com o interdiscurso, a relação com os sentidos. Segundo Orlandi (2012b, p. 171), "no próprio texto, em sua constituição, há gestos de interpretação que mostram a ou as posições do sujeito que o produziu. Compreender significa então explicitar os gestos de interpretação feitos pelo sujeito, gestos estes inscritos no texto".

A teoria privilegia os sentidos presentes no discurso, os quais o sujeito busca interpretar. Isso porque o sujeito é fadado a interpretar, lendo a partir de sua posição-sujeito e refletindo sobre as condições de produção de sua leitura. Assim, a posição-sujeito é heterogênea e está ligada às filiações desse sujeito com a FD que se manifesta, diferentemente da posição enunciativa que está relacionada aos papéis sociais exercidos pelo sujeito.

Além dessa distinção, Orlandi (2010) relata que o sujeito da AD não é o sujeito empírico, mas sim, é efeito de e da linguagem, ou seja, é “a posição-sujeito projetada no discurso. Isto significa dizer que há em toda língua mecanismos de projeção que nos permitem passar da situação sujeito para a posição sujeito no discurso" (Orlandi, 2010, p. 15). Desta forma, percebe-se que existem diferentes posições enunciativas que o sujeito pode ocupar (lugares sociais: chefes, professores, alunos, pais, etc.) e por meio delas é que se vai produzir o discurso. Estas posições são determinadas por representações imaginárias e pela estrutura socioeconômica e pela ideologia.

Deste modo, “a posição-sujeito e o sentido são relativos à inscrição a uma formação discursiva do dizer" (idem, p. 17). Isso evidencia que, na constituição do texto, há gestos de interpretação produzidos pela ou pelas posições do sujeito. Como aborda Orlandi

Não há sujeito, nem sentido que não seja dividido, não há forma de estar no discurso sem constituir-se em uma posição-sujeito e, portanto, inscrever-se em uma ou outra formação discursiva que, por sua vez, é a projeção da ideologia no dizer. As relações de poder são simbolizadas e isso é o político. (ORLANDI, 2012b, p. 55)

Assim, devem-se buscar os sentidos que se ocultam nas práticas discursivas. $\mathrm{O}$ analista busca, então, tecer o fio dos enunciados dispersos que estão na base do dizível e do não dizível da superfície discursiva, mergulhando no universo dos discursos que produzem e emergem os efeitos de sentidos desses enunciados, que constituem saberes/poderes e transitam nos processos de subjetivação dos sujeitos.

Para a AD, o sujeito e os sentidos são constituídos no/pelo discurso. Isso porque as palavras e as expressões mudam de sentido conforme as posições sustentadas por aqueles que as empregam. Assim, é necessário evidenciar o sujeito como uma posição e como um lugar que ocupa para ser sujeito do que diz, pois quando se diz algo, se silencia outros dizeres. Para Orlandi (2012a, p. 
49), "se ele não se submeter à língua e à história ele não se constitui, ele não fala, não produz sentidos.”.

O dizer possibilita uma reflexão sobre o silêncio, algo que significa, um não-dito que pertence à linguagem e cria um efeito de sentido próprio. $\mathrm{O}$ silêncio, na sua composição primária, indica a possibilidade de imaginação, a noção de interrupção do pensamento e da falta do dizer. No entanto, a linguagem sugere silêncio, o silêncio é a própria condição de produção da linguagem. É pelo silêncio que se evidencia a possibilidade, porque quanto mais ausência, mais probabilidade de sentidos existe.

Na materialidade linguística, as reticências marcam esse silêncio que, em sua complexidade, produz efeitos de sentido na relação entre o dizer e o não dizer. Por isso, os sentidos não são evidentes e não cessam, pois os sentidos estão junto com o silêncio, com aquilo que não é dito. Esse não-dito é o espaço deixado à interpretação do sujeito e sinalizado pelas reticências, que evidencia o não acabamento do texto e a permissão da construção de sentidos. Esse sentido, que representa a incompletude da linguagem, fica aparente com o uso da pontuação. E assim, o silêncio que pode surgir das próprias palavras, também pode aparecer pela omissão das palavras. A palavra aparece como movimento em torno do silêncio (GRANTHAM, 2002).

Segundo Orlandi (2012a), o silêncio tem significação própria e, assim, existem distintas formas de explicar o silêncio. O silêncio fundador é o indício de uma totalidade significativa, isto porque ele movimenta os sentidos e perpassa as palavras, "indica que o sentido pode sempre ser outro" (idem, p. 82). Já a política do silêncio separa-se em silêncio constitutivo, em que certas palavras são ditas em favor do apagamento de outras, "para dizer é preciso não-dizer" (idem, p. 82) e, silêncio local, que se refere ao que não é dito, “aquilo que é proibido dizer em uma certa conjuntura" (idem, p. 82).

Salienta-se que o sentido pleno está no silêncio e o silêncio fundador é o princípio da linguagem porque significa por si só, diferente da política do silêncio que pode produzir algo entre o que se diz e o que não se diz. Quando é necessário dizer para não-dizer, evidencia-se a inserção do sujeito em uma FD historicamente determinada e isso se refere ao limite do dizer no silêncio constitutivo. A política do silêncio define-se pela razão de que, ao dizer algo, apagam-se outros sentidos possíveis, mas indesejáveis, em uma FD dada. E quando o sujeito não pode dizer, é impedido pela censura, o sentido se enfraquece (ORLANDI, 2012a).

Esse silêncio é repleto de sentidos, que vem tanto do autor e do leitor, quanto de outros textos e de outros discursos. Neste sentido, reflete-se sobre as reticências que significam por si próprias. No emprego deste sinal de pontuação, abre-se um espaço para o sentido, sentido esse dado pela interrupção do discurso que significa (GRANTHAM, 2002). Assim, percebe-se a construção de um silêncio que significa sem palavras.

O sujeito, que deixa este espaço do dizer preenchido pelas reticências, faz isso determinado ideologicamente, inscrito em uma FD, assumindo uma certa posição-sujeito. Desta forma, as reticências permitem a produção de sentidos por 
(adernos de ESTUDOS LINGḯlsTICOS (57.2) - Jul./Dez. 2015

ser um sinal do silêncio do discurso (GRANTHAM, 2002). Portanto, devem-se procurar os sentidos que se encobrem nas práticas discursivas. E o analista, ao observar os discursos que se produzem e no qual emergem os efeitos de sentidos dos mais variados enunciados, busca revelar, por meio dos dizeres, os processos de subjetivação dos sujeitos.

\subsection{Corpo na mídia}

Nos estudos em AD, novos objetos estão ganhando espaço. Dentre eles, destacam-se as discussões sobre corpo, constituindo um novo tipo de discurso a ser analisado. Desta forma, o corpo torna-se um campo de materialidade do sujeito, envolvendo diferentes práticas e saberes sócio-históricos. O corpo é a forma de expressão do ser humano, servindo para demonstrar sua presença física, social e cultural. Segundo Orlandi (2012b, p. 86), “o corpo do sujeito está atado ao corpo da cidade, ao corpo social". A expressão do sujeito por meio do seu corpo reflete saberes ligados a diversos contextos sócio-históricos e culturais. E este corpo torna-se um produto social que produz sentidos através de práticas, atitudes e relações.

No século XX, os valores morais transformaram-se juntamente com a tendência à padronização dos corpos. A mídia, neste contexto, teve um papel fundamental na construção e consolidação de certos padrões corporais e estéticos, visto que os sujeitos constroem-se, principalmente, através do corpo e da imagem que projetam (GARCIA, 2005). Por meio dessa construção, percebese o crescimento das cobranças exercidas pela mídia, que tendem a aprisionar o corpo feminino, como também o corpo masculino. Assim,

um conjunto de regras, um trabalho cotidiano das aparências, de complexos rituais de interação, a liberdade de que cada um dispõe para lidar com o estilo comum, com as posturas, as atitudes determinadas, os modos usuais de olhar, de portar-se, de mover-se, compõem a fábrica social do corpo. (CORBIN, 2008, p. 8-9)

Na cultura atual, notáveis são as marcas que potencializam o olhar sobre o corpo e a ditadura da "boa forma" (GARCIA, 2005). Ressalta-se que o discurso sociocultural entre os sujeitos revela as relações contextualizadas sobre o culto ao corpo. Por isso, o corpo "emerge como mecanismo linguístico que pondera sua forma em um tecido enunciativo; ele deixa de ser mero objeto orgânico para transformar-se em linguagem, que enuncia e agrega valores socioculturais." (GARCIA, 2005, p. 27)

A constante mudança em relação à conectividade, à integração e à interdependência das esferas da vida, como a tecnológica, cultural, econômica e social, geraram efeitos significativos na vida cotidiana, refletindo, também, no peso do corpo (SANT'ANNA, 2001). Nesse sentido, a mudança corporal pode ser percebida, interpretada e influenciada por valores socioculturais, variando de uma sociedade para outra, nos diferentes contextos históricos e também entre diferentes grupos sociais. Não há como negar que a obesidade está relacionada "às maneiras de viver e às condições efetivas de vida e saúde de sociedades, 
classes, grupos e indivíduos que são construções históricas e sociais" (BRASIL, 2006, p. 21).

O que se percebe é uma determinação social dos padrões corporais ideais e dos que estão fora dos padrões e que são portadores de um estigma social. Com isso, homens e mulheres sentem-se rejeitados em seus grupos e em espaços públicos por não se enquadrarem nos parâmetros corporais aceitáveis socialmente e reconhecidos culturalmente como "normais". Assim, o uso da expressão "gordo" pode mostrar as inúmeras discriminações recebidas pelas pessoas que não pertencem aos padrões sociais hegemônicos, o que acarreta em inferiorização e exclusão do sujeito.

Assim, compreende-se que não existe corpo que não esteja investido de sentidos. Sentidos oriundos do sujeito moderno interpelado em sujeito pela ideologia, afetado pela língua e que tem a necessidade de interagir e criar laços sociais. Logo, considera-se a questão do corpo do sujeito como alvo dos novos mecanismos do poder, como a mídia, que também oferece novas formas de saber. Orlandi reforça esse saber, ao dizer que

o corpo do sujeito é, nas condições sócio-históricas em que vivemos, parte do corpo social tal como ele está significado na história. Isto quer dizer, entre outras coisas, que o sujeito relaciona-se como o seu corpo já atravessado por uma memória, pelo discurso social que o significa, pela maneira como ele se individualiza. (ORLANDI, 2012b, p. 93)

Esse discurso é transmitido pela mídia, uma instituição promotora de saberes, que estabelece padrões de beleza, através da ideia de corpo magro como garantia de saúde e bem-estar, instituindo maneiras para atingir um ideal. Contudo, há controle do que se pode e do que se deve dizer. Os sujeitos que, ao mesmo tempo, adquirem a liberdade em mostrar os seus corpos, aprisionam-se em critérios estéticos, pois acreditam ser necessário ter a forma padrão ideal. Isso permite a reflexão quanto à grande influência do capitalismo, que exige sujeitos socialmente ativos. Segundo Orlandi (2012b, p. 93),

quando digo que o corpo já vem significado, penso ideologicamente, ou seja, na imagem que fazemos de um corpo ocidental ou oriental, ou como pobre ou rico, como homem, mulher ou homossexual etc. Sentido já dados. Estabelecidos e estabilizados. Ou seja, estou pensando que "os modos de produção da vida material condicionam o conjunto dos processos da vida social e política".

O corpo, assim, tem um sentido próprio, um sentido estabelecido, que emerge pela ideologia que permeia a sociedade de consumo atual. Deste modo, o "corpo não escapa à determinação histórica, nem à interpelação ideológica do sujeito" (idem, p. 95). E por isso, ao se debruçar sobre os objetos midiáticos, notam-se as ferramentas de manipulação e controle de como se chegar ao corpo perfeito, uma vez que ele é a condição para estar na ordem do discurso da beleza feminina.

Para a AD, a relação intersubjetiva e a mídia são espaços específicos de produção de linguagem (discursos). Discurso esse que se apresenta por meio de 
Cadernos de ESTUDOS LINGüISTICOS (57.2) - Jul./Dez. 2015

linguagens verbais e não-verbais, em que jogam distintas posições enunciativas em um conjunto heterogêneo de práticas discursivas. Na materialidade linguística, apresentada por um sujeito que está na posição de público, emerge um imaginário em que se relacionam os interlocutores. E, assim, a novela faz parte do funcionamento desse imaginário que compõe e expande os discursos da sociedade urbana e os discursos de mercado (capitalista). Em uma entrevista ${ }^{4}$ , Orlandi relata que a forma-sujeito-histórica do sujeito moderno é a forma capitalista, caracterizada como sujeito jurídico, com seus direitos e deveres e sua livre circulação social.

Na sociedade atual, os sujeitos são interpelados pela ideologia capitalista diariamente. Todos os dias, assistir televisão, navegar na internet e falar no celular são hábitos comuns para muitos sujeitos. Essa popularização tecnológica permite a difusão de informações que podem influenciar as pessoas no modo de agir, pensar e vestir, criando demandas e orientando estilos e discussões sociais. A novela é um exemplo disso, pois, através da ficção, apresenta modelos de comportamento, beleza e moda que se modificam e recebem a atenção dos telespectadores. Com isso, as tendências e os padrões de beleza surgem e, ao se difundir, são copiados, seguidos e aceitos pelos sujeitos que interagem com a mídia.

E assim, a imagem de passividade do telespectador é substituída pela imagem de interatividade do internauta que, por meio de seu discurso, cria diferentes efeitos de sentido para as produções das personagens televisivas. Deste modo, esse sujeito, que é leitor, telespectador, navegador, internauta, interage de diferentes formas e é interpelado pela ideologia e pelo inconsciente, refletindo sua posição-sujeito.

Segundo Recuero (2009), o uso crescente de redes como a Internet resultou na criação de um novo tipo de organização social, a sociedade em rede, que permite a formação de comunidades virtuais, grupos humanos constituídos pela identificação de interesses comuns. Neste contexto, as conexões e interações no domínio das redes sociais acontecem pela mediação da Internet, do telefone ou outro meio tecnológico. E, desta forma, o conteúdo das relações é o que precede e alimenta os laços sociais entre os indivíduos e acrescenta um valor de grupo ou comunidade para a interação social (RECUERO, 2009).

Os laços sociais, elemento constituinte das conexões, são formados a partir das relações ou das interações (RECUERO, 2009). Estes laços, oriundos de interações tanto virtuais quanto face a face, permitem que o sujeito signifique e se signifique dentro e fora do espaço virtual. Neste sentido, a autora aborda que "as pessoas adaptaram-se aos novos tempos, utilizando a rede para formar novos padrões de interação e criando novas formas de sociabilidade e novas organizações sociais" (idem, p. 89).

\footnotetext{
${ }^{4}$ Entrevista para Raquel Goulart Barreto, publicada em 2006, na revista Teias, intitulada “Análise de Discurso: conversa com Eni Orlandi”. Disponível em: <http://www.periodicos.proped. pro.br/index.php/revistateias/article/view/210 > Acesso em: 15 jul. 2015.
} 
É preciso salientar que este estudo centra-se no Facebook, mais precisamente em uma página de fãs, fanpage, que possibilita a utilização de diversos aplicativos como enquetes, discussões sobre determinados temas, galeria de fotos e vídeos para a interação com os seguidores. No Facebook, o sujeito seleciona a fanpage que quer fazer parte, tendo em vista seu interesse particular em um ou mais assuntos com os quais se identifica e onde encontra pessoas com quem pode compartilhar ideias e gerar discussões.

Com isso, Recuero (2013) aborda que as formações das redes sociais são a base para entender este novo ambiente de comunicação mediada pelo computador. O que revela a interação e a construção de laços no Facebook é, principalmente, a opção "curtir". O ato de "curtir" uma página é uma forma de demonstrar identificação com o texto e as imagens postadas (RECUERO, 2013). A partir do sentimento de pertencimento, as pessoas passam a interagir, de maneira a se relacionarem e promoverem trocas comunicacionais através dos compartilhamentos ou mesmo comentários.

$\mathrm{Na}$ página principal da fanpage "Só Gordinhas" observamos que, em julho de 2013, ela possuía mais de 323.111 curtidas e 11.235 pessoas "falando sobre isso". Para Recuero (2009), esses dados demonstram que a relação entre audiência (quantidade de pessoas que curtem a página) e engajamento não é proporcional, visto que há muitas curtidas e poucos comentários. Por meio dos comentários gerados através da postagem publicada na fanpage, será realizada a análise da materialidade discursiva e dos efeitos de sentidos produzidos nesta FD de "aceitação do corpo" e representativa das internautas.

\section{DA TEORIA ÀS ANÁLISES}

A fanpage "Só Gordinhas" do Facebook, criada em 3 de abril de 2012, possui mais de 323 mil curtidas, evidenciando uma boa manutenção dos laços sociais das administradoras com seus seguidores. A fanpage aborda temáticas relacionadas à beleza feminina, à autoestima, à valorização do corpo voluptuoso e ainda, à problemática que diz respeito ao preconceito atribuído à mídia eletrônica. A interpretação, mediante aos pressupostos teóricos já apresentados, é apenas uma das tantas possibilidades de análise que a materialidade discursiva da fanpage propicia ao analista.

Nesta análise, serão verificados os comentários referentes a uma postagem indicada por uma seguidora na fanpage, relacionada ao posicionamento das internautas em relação à personagem Perséfone da novela "Amor à Vida" da Rede Globo. A análise realizada contou com a observação dos 38 comentários, sendo seis deles escolhidos por serem postados no dia 5 de junho de 2013, no mesmo dia da postagem que dá início à discussão, e 15 dias após o início da novela, que foi em 20 de maio, revelando o possível tempo necessário para identificar as características das personagens. Através do discurso, pretende-se mostrar os efeitos de sentido que são produzidos na FD revelada, evidenciando as diferentes posições-sujeito que adquirem sentido e permitem sentidos através das reticências em referência às formações ideológicas. 
2.1. A composição discursiva da fanpage "Só Gordinhas"

Só gordinhas

Quarta próximo a Recife

Gente enquete sugerida por uma de nossas lindezas, vejam só... (:)

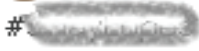

Adoro esse cantinho aqui no facebook do so gordinhas... Queria apenas que fosse aberto um tópico aqui para dar-mos nossa opiniẫo sobre a personagem gordinha representada pela (Fabiana Karla) na novela A.mor a Vida. O q vcs estão achando da personagem caricaturada de virgem ( sinônimo de encalhada pa novela) e que pra arranjar alguém tem que ser empurrada p lá e pá cá pelos personagens da novela... vcs vêem isso como normal ou vêem outra maneira de serem preconceituosos mais uma vez com agente?

\section{Curtir · Comentar ' Compartilhar}

[3 53 pessoas curtiram isso.

Figura 1: Postagem inicial da administradora

A postagem inicial ${ }^{5}$ sobre a personagem Perséfone, da novela "Amor à Vida" da Rede Globo, teve 38 comentários e 53 pessoas curtiram o tópico. Essa postagem refere-se à figura 1. A chamada aos seguidores começa com "Gente", forma usada sem distinção de gênero e modificada no decorrer do enunciado através da expressão "nossas lindezas", determinando a importância da participação do público feminino, tanto nas pautas de discussão, quanto nas respostas dadas à enquete. É preciso realçar que a contribuição da enquete é de uma seguidora da fanpage "Só Gordinhas" que foi adicionada ao local pela administradora que aparece após a hashtag. O Facebook ${ }^{6}$ expõe que "as hashtags transformam tópicos e frases em links clicáveis em publicações da sua linha do tempo pessoal ou página. Isso ajuda às pessoas a encontrar publicações sobre tópicos nos quais eles estão interessados." Com isso, o uso da hashtag ( sinal \#) como um indicativo contextual daquilo que é dito no Twitter, é também usado no Facebook. No entanto, o nome da administradora aparece após o símbolo de hashtag, que, diferente do uso habitual abordado, é utilizado para apresentar quem fez a postagem, visto que a fanpage conta com mais administradoras.

\footnotetext{
${ }^{5}$ Postagem observada em 25 de junho de 2013.

${ }^{6}$ Central de ajuda. Como faço para usar hashtags? Disponível em: $<$ http://pt-br.facebook.com/ help/587836257914341> Acesso em: 10 ago. 2013.
} 
A utilização do internetês, linguagem utilizada no mundo virtual que preconiza a agilidade e a facilidade de escrita, é apresentada na postagem pela diminuição das palavras, apagamento de acentos e pontuações, mas que não acarretam problemas para a compreensão do leitor. Cabe ressaltar que essa linguagem é entendida e atinge o público alvo pretendido.

Também, revela-se na postagem a caracterização da personagem, que em vez de ser chamada pelo nome é tratada como "personagem gordinha" e "caricaturada de virgem". Isto aponta para uma escolha linguística da internauta que sugeriu a postagem para a administradora, podendo ser justificada pelo início recente da novela, como, também pela identificação rápida sobre quem está sendo abordado na enquete.

Percebe-se, ainda, a utilização das reticências que marcam a continuidade do dizer, abrindo um espaço para o sentido, sentido esse dado pela interrupção do discurso que significa, permitindo que as internautas imaginem e comentem.

Nos comentários apresentados pelo público seguidor da página surgem alguns referentes que caracterizam o grupo, como o uso das expressões "fofinhas, nossas lindezas, nós gordinhas, nós mulheres gordinhas, mulheres que estão acima do peso e gordelícias". Essas expressões apresentam um pouco da constituição da forma-sujeito que configura a FD de "aceitação do corpo" frente ao lugar de dizer utilizado para a interação, o que reforça a necessidade de valorização da constituição física e psicológica.

Essa materialidade discursiva, encontrada na fanpage e observada em enunciados de mulheres sobre a personagem Perséfone da novela da Rede Globo, está inscrita numa FD de "aceitação do corpo" configurada por discursos identificados com os saberes compartilhados pelas mulheres acima do peso, representativos do discurso da Rede Globo e que apontam a existência de preconceito. Essa FD que determina aquilo que pode e deve ser dito é composta por diferentes posições-sujeito que serão apresentadas no decorrer desta análise.

\subsection{Comentários das internautas}

Como o discurso é composto por diferentes posicionamentos, analisar-se-á o primeiro comentário (Figura 2), que trata a questão da visão de estereótipo de corpo, evidenciando o que possivelmente as "gordinhas" vivenciam, um saber próprio relacionado ao preconceito.

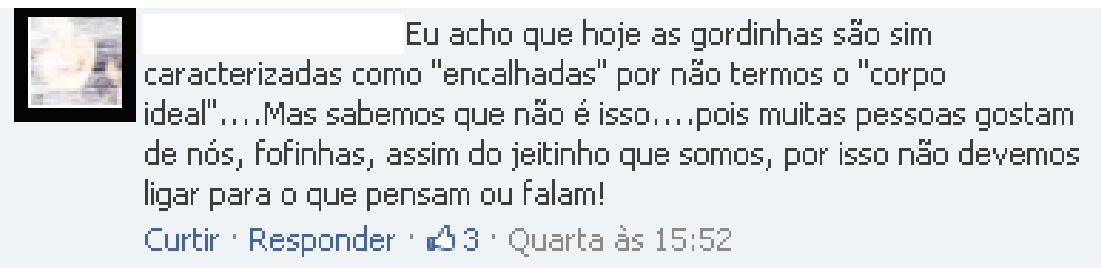

Figura 2: Comentário de uma seguidora 
O primeiro exemplo (Figura 2) afasta-se da questão da personagem da novela e trata do que as mulheres "gordas" podem vivenciar. No início do primeiro enunciado, "Eu acho que as gordinhas são sim caracterizadas como "encalhadas", o discurso da seguidora afasta-se do estereótipo, demonstrando uma evidência do preconceito embutido pela sociedade e pela mídia, e no decorrer de seu dizer "por não termos o 'corpo ideal'...", ela inclui-se, revelando um encaixe na característica. Esse posicionamento pode evidenciar a existência da ideologia preconceituosa, quando o estereótipo de corpo fora de padrão relaciona-se ao de "encalhada".

Assim, a primeira evidência de preconceito é apresentada pela materialidade discursiva: “as gordinhas são sim caracterizadas como 'encalhadas' por não termos o 'corpo ideal'...". Neste enunciado, observamos o uso de aspas para chamar atenção para os sujeitos que levam esse padrão em consideração, mas a internauta só se inclui na questão da padronização da beleza corporal. Ainda, para finalizar o comentário, observam-se as reticências que remetem a um acréscimo de sentidos do que seria apropriado não dizer ou que permite ao leitor criar um sentido próprio em relação ao preconceito apresentado.

Em seguida, o dizer da seguidora reforça que não é apenas isso, pois as reticências mostram que há uma possível ideia da internauta, de que algo a mais precisa ser pensado e dito, mas não de qualquer forma. Por isso, a exposição de "Mas sabemos que não é isso...", revela um silêncio que apresenta uma possibilidade de sentidos outros e de não acabamento do texto, uma ausência enunciada. $\mathrm{Na}$ continuidade da exposição, o dizer "pois muitas pessoas gostam de nós, fofinhas, assim do jeitinho que somos" traz os referentes "nós, fofinhas", mostrando que a seguidora pode pertencer e se identificar com esse grupo social e que a importância maior deve estar direcionada àqueles que não se importam com esse padrão.

Para finalizar a exposição, a internauta sugere às demais seguidoras da fanpage que mantenham uma postura de distanciamento de argumentos preconceituosos, por meio do dizer "não devemos ligar para o que pensam ou falam!". Esse comentário recebeu três "curtidas" das demais seguidoras, o que comprova certa aprovação do enunciado produzido, através de identificação com o texto postado, e a possível construção de laços nas redes sociais.

O comentário a seguir apresenta uma forma de admiração e aceitação do papel da personagem e a percepção da não presença do preconceito.

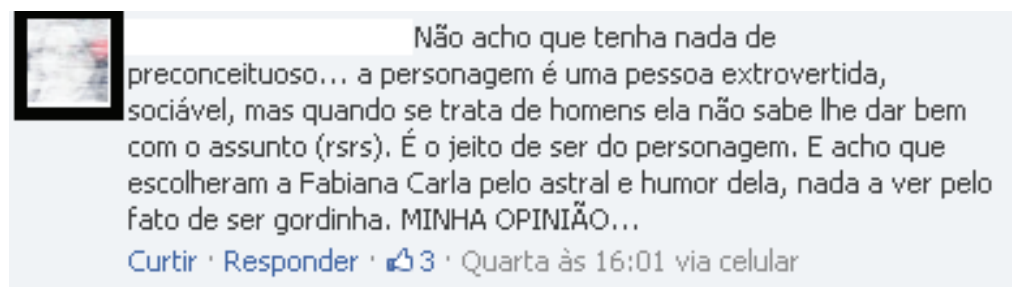

Figura 3: Comentário de uma seguidora 
O comentário da internauta (Figura 3) tem uma abordagem que trata do preconceito e da postura da personagem Perséfone. No enunciado "não acho que tenha nada de preconceituoso...", a internauta expõe duas negações com "não" e "nada", o que pode evidenciar uma ideia de intensidade e de confirmação do que diz. O uso das reticências reflete a continuidade de uma afirmação que poderia ser completada com mais adjetivos, sentido que possibilita que o leitor imagine.

Ao tratar da representação da atriz, há uma visão da dramatização e da importância das características da atriz ao apresentar sua personagem. A atriz tem "astral e humor" e a personagem é "extrovertida e sociável", o que faz com que elas comunguem de adjetivos parecidos. A forma física não é abordada inicialmente e não está imbricada com as demais características. A ironia faz-se presente pelo do uso do "rsrs" ao tratar da forma como a personagem relaciona-se com os homens.

Também, observa-se, na sequência "MINHA OPINIÃO...", o uso do internetês pela inserção das letras em caixa alta que remete à voz alta ou gritos, o que pode ser atribuído ao posicionamento firme da internauta quanto à questão corporal envolvida com a personagem. O fato de a atriz ser "gordinha" não tem relação com o papel da personagem, mas sim com o "jeito de ser do personagem". Esse jeito de ser também permite sentidos diversos, pois cada sujeito tem sua forma de pensar e sua constituição sócio-histórica e cultural. Essa postagem permite que o sujeito-leitor amplie os sentidos que seriam remetidos pelo nãodito, não só pelo uso das reticências, mas, também, pelas palavras utilizadas neste espaço enunciativo.

Os dois próximos comentários abordam o que algumas seguidoras percebem no discurso da emissora da rede Globo a partir da representação da personagem.

\section{$\square$ Acho que a rede globo poderia ter um repertorio bem mais interessante para a atriz ela é linda! Assim como nós..... Curtir ' Responder ' Quarta às 16:27 via celular}

Figura 4: Comentário de uma seguidora

Esse comentário remete uma postura que se volta contra o discurso da emissora de televisão e valoriza o papel da atriz. A atriz é vista como representante das mulheres que estão acima do peso, ditas gordas. A expressão "ela é linda" afirma essa posição que é reforçada pelo enunciado seguinte. A questão a ser entendida é o que mais elas são, pois ao dizer "assim como nós...", a internauta diz que são mais que lindas e, o silêncio, referenciado na sequência discursiva, permite mais atribuições que possam estar relacionadas à personagem, à atriz e às internautas da fanpage.

No entanto, precisamos atentar para o início da sequência que trata do "repertório" dado à atriz que, aparentemente, não é condizente com o que a internauta esperava que fosse apresentado. O posicionamento da emissora da rede Globo é referenciado novamente na próxima postagem e agora tratada como preconceituosa, é o que será visto a seguir. 
Figura 5: Comentário de uma seguidora

Esse enunciado (Figura 5) aborda diretamente o que representa a emissora de televisão para esse sujeito discursivo através da expressão "E Tinha que ser a Globo... como sempre "pra lá de preconceituosa!". Com isso, compreende-se um dos posicionamentos do sujeito que julga o que a personagem vive como preconceito, o que mostra a presença da forma-sujeito da FD que, de maneira ilusória, determina o saber do sujeito sobre as mulheres gordas.

A seguidora utiliza-se das reticências para expor que algo a mais precisaria ser dito, além do que foi abordado pelas palavras, que enunciam sua indignação frente ao que a emissora de televisão apresenta. No entanto, com o uso da pontuação, ela não diz para dizer, esse algo a mais, poderia ser pensado pelo leitor, sentidos que poderiam ser imaginados, mas não determinados, pois a falta das palavras irá significar algo. Com isso, percebe-se que a seguidora, inserida numa FD de "aceitação do corpo" historicamente determinada, movimenta os sentidos, perpassando as palavras, mas também utilizando essas palavras em prol do apagamento de outras.

Ainda, o discurso da seguidora ao expressar "ridículo, inadimissível" expõe uma percepção da representação da personagem. Esta expressão, reiterada pelas palavras, éreveladora daposição-sujeito daseguidora. Odicionário Michaelisonline ${ }^{7}$ apresenta para o vocábulo "ridículo" os seguintes significados: como adjetivo, "digno de riso, de escárnio, de zombaria; que se presta ao cômico; irrisório; insignificante" e, como substantivo, "ato, discurso ou palavras com que se ridiculariza alguém, escárnio, zombaria, irrisão; maneira ridícula de ser ou de proceder", revelando o papel que a personagem vive na novela e que é parte do que compõe a emissora. A segunda palavra, "inadmissível", no dicionário, apresenta o significado de algo "que não se pode admitir, aceitar ou receber". Assim, os dois vocábulos juntos expõem que a emissora, ao dar a personagem um papel cômico, tem um discurso inaceitável na visão da seguidora.

O dizer desse sujeito discursivo revela uma posição marcada, podendo ser uma forma de demonstrar o preconceito que a seguidora possa ter vivenciado. O que parece não contar para essa internauta são os papéis feitos pela atriz, que trabalha com humor, e que a representação da personagem tem relação com sua trajetória como comediante e atriz de novela.

A posição-sujeito, identificada com os saberes compartilhados pelas mulheres gordas, corrobora para a valorização da mulher vista pela sociedade

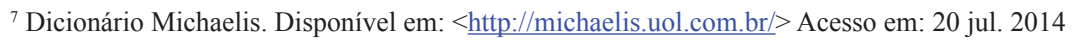


como robusta, voluptuosa, corpulenta e que está fora dos padrões ditados pela mídia. Pela materialidade discursiva, verifica-se a necessidade das seguidoras em mostrar o quanto estão satisfeitas consigo mesmas e que precisam ser valorizadas. Isto pode ser observado no próximo comentário.

Infelizmente e a realidade... mas acredito que no meio vão mostrar o qto somos poderosas e capazes de ter alguém. Sou gordinha e feliz e sempre consigo o que quero com meu carisma e auto astral. .. até pq somos humanas e sentimos como qualquer outro ser humano.

\section{Curtir · Responder ' Quarta às 16:23 via celular}

Figura 6: Comentário de uma seguidora

Neste exemplo (Figura 6), o uso do internetês é visto através das palavras abreviadas "qto" e "pq" e do apagamento do acento agudo de "e". Percebe-se que a seguidora utiliza a Internet no aparelho móvel por meio da expressão "via celular" ao lado do dia e da hora da postagem. Também, verifica-se o uso do verbo ser na primeira pessoa do plural no presente do indicativo, "somos", e dos adjetivos "poderosas" e "capazes", demarcando a inserção da seguidora nesse discurso de valorização própria e a utilização de "gordinha" e "feliz" que define a forma como ela se caracteriza. Os substantivos abstratos "carisma" e "alto-astral" intensificam novamente os atributos que as mulheres gordas necessitam ter.

$\mathrm{O}$ que reforça e remete à possibilidade de mais atributos são as reticências as quais revelam que algo a mais precisa ser dito, preenchido pelo leitor, criando sentidos outros, qualidades permitidas. Desta maneira, o discurso lançado pela seguidora está atrelado a uma visão imaginária de que a mulher gorda precisa ter mais atributos do que uma pessoa dentro dos padrões estéticos, o que pode estar constituído na sua formação ideológica.

Ainda, nesse exemplo, analisa-se a presença de uma segunda posição-sujeito que se identifica com o discurso da Rede Globo. Isso se constitui no enunciado "Infelizmente é a realidade...", que traz à tona a ficção, a vida da personagem gorda e virgem, como algo que aconteça no cotidiano dessas mulheres. Esse dizer pode ser entendido como uma constituição histórica e ideológica desse sujeito interpelado na/pela linguagem e que, por meio do uso das reticências, sugere uma continuidade de seu dizer. Esse sujeito-mulher configura sua posição-sujeito através de uma imagem de si valorizada, aproximando seu dizer à representação da personagem e do interlocutor imaginado, que possivelmente pode identificar-se com seu discurso.

Nesse contexto, em que o sujeito discursivo identifica-se com o discurso da Rede Globo, de forma que a representação midiática da personagem é aceita pelas seguidoras da fanpage, apresenta-se outro discurso. 


\section{Curtir ' Responder ' Quarta às 16:26}

Figura 7: Comentário de uma seguidora

Essa sequência discursiva (Figura 7), primeiramente defende a postura da rede Globo, nas novelas, ao apresentar assuntos relevantes como "virgindade, peso fora dos 'padrões', idade e etc." que podem repercutir na vida das pessoas. Nessa enunciação, aparece o uso de aspas na palavra "padrões" que nos leva a pensar que ela não aceita os estereótipos de corpo alicerçados pelos meios de comunicação.

No entanto, o discurso dessa seguidora esclarece a necessidade de refletir sobre as questões que a mídia expõe, assimilando apenas o que pode ser útil à sua vida. Com isso, sua posição fica no entremeio da importância da reflexão para perceber os prós e contras dos posicionamentos midiáticos apresentados. Aqui demonstrados pelas expressões "lado bom (para pessoas que acabam refletindo a partir do que é mostrado)" e "lado ruim, para quem engole tudo o que a Globo mostra sem nem sequer pensar...". Além disso, as reticências demonstram que a seguidora dá um indicativo de uma totalidade significativa, utilizando-se do silêncio fundador sem perceber, pois ela revela pelo seu discurso que o silêncio movimenta os sentidos e perpassa as palavras, indicando que o sentido pode sempre ser outro.

A materialidade discursiva, apresentada no espaço virtual da fanpage pelos exemplos de postagens, deu suporte para se evidenciar a presença de ideologias que compõem a FD de "aceitação do corpo" representada. Essa FD, que configura o discurso do sujeito, interpelado pela ideologia, intervém pelos saberes ideológicos apresentados pela mídia e a filiação desses sujeitos à determinada FD, que contém várias posições-sujeito. Essas posições-sujeito são heterogêneas e apresentam diversas maneiras de expressar a forma-sujeito, que é resultante da socialização do sujeito, através de convergências, divergências e predominâncias. Com isso, esse sujeito-mulher com diferentes posicionamentos busca na sua constituição a aceitação e a valorização do próprio corpo pela sociedade.

\section{CONSIDERAÇÕES FINAIS}

Pela análise realizada, percebe-se a influência que a mídia exerce na opinião e na vida das pessoas. A mídia revela normas que, de certa forma, são aceitas pela sociedade. E estas normas são propagadas por ideologias que atravessam o sujeito, que, inconscientemente, vira refém dos ditames de padronização cultural como 
a beleza corporal. Esse sujeito, interpelado pela ideologia e pela linguagem em sujeito, faz críticas à mídia e à sociedade atual, mas não consegue se desvencilhar das normatizações sócio-históricas e culturais que o constituem e o fazem significar.

Esse sujeito, a partir de seu discurso, observado no espaço virtual da fanpage "Só Gordinhas" apresenta as convergências/divergências das posições-sujeito que constituem a FD de "aceitação do corpo". A forma-sujeito, aparentemente, gira em torno da aceitação e valorização própria das mulheres gordas com seus diferentes posicionamentos. Essas posições-sujeito evidenciam discursos sobre estereótipos de corpo, a existência de preconceito, a valorização e a importância dada à aparência física e a valorização dada à representação da personagem na novela. Aliando-se a isso, pode-se tratar da identificação das seguidoras da fanpage com o papel da personagem e sua crítica positiva e negativa em relação ao discurso da rede Globo.

A materialidade discursiva, apresentada pelos sujeitos que participam dessa fanpage, mostra um discurso de defesa da aceitação da aparência que a mulher possui e uma crítica à normatização da mídia televisiva, que remete ao preconceito evidenciado pela personagem. E assim, essa materialidade remete para a questão sócio-histórica, referente à razão pela qual uma mulher gorda precisa ser simpática, como a personagem, e da certeza de que o preconceito deve ser banido do contexto sócio-histórico e cultural atual. Deste modo, os enunciados produzidos criaram diferentes efeitos de sentido, evidenciados pelas posições-sujeito, assumidas pelos sujeitos que pela linguagem, significaram e demonstraram que o corpo é expressão significante neste jogo de relações de força.

Também, o uso frequente das reticências é algo que significa sem palavras. Isto porque o sujeito está inevitavelmente destinado a significar, mas não fundamentalmente a falar/escrever e com isso, a pontuação revela os possíveis sentidos outros. Desta forma, o silenciamento das seguidoras da fanpage, em alguns dizeres, produziu sentidos que revelaram possibilidades de interpretação, evidenciados pelas reticências, mostrando apagamentos, talvez indesejáveis ou não permitidos naquele espaço virtual.

O espaço enunciativo, apresentado pela fanpage, mostra a regularidade do uso da linguagem das redes sociais e a disponibilidade de acesso às redes sociais através de aparelhos móveis. As administradoras da fanpage mantêm boa popularidade, visto que utilizam essa rede social para manter seus laços sociais. Neste contexto, a interpretação realizada é apenas uma das tantas possibilidades referentes aos pressupostos teóricos utilizados, visto que muitas são as interpretações possíveis, pois a língua e os sentidos estão em constante movimentação.

\section{$\overline{\text { REFERÊNCIAS BIBLIOGRÁFICAS }}$}

BRASIL. Ministério da Saúde. Secretaria de Atenção à Saúde. Departamento de Atenção Básica. Obesidade. Brasília: Ministério da Saúde, 2006. (Cadernos de Atenção Básica, n. 12) 
$\overline{\text { CORBIN, A. O encontro dos corpos. In: CORBIN, Alain; COURTINE, Jean-Jacques; VIGARELLO, }}$ Georges. História do corpo: Da Revolução à Grande Guerra. Trad. João Batista Kreuch; Jaime Clasen. Vol. II. 2. ed. Petrópolis, RJ: Vozes, 2008. p. 181-266

COURTINE, J-J. Análise do Discurso Político: o discurso comunista endereçado aos cristãos. São Paulo: EdUFSCar, 2009.

FOUCAULT, M. A ordem do discurso. Trad. Sírio Possenti. Ijuí: Fidence, 1973.

GARCIA, W. Corpo, mídia e representação: estudos contemporâneos. São Paulo: Pioneira Thomson Learning, 2005.

GRANTHAM, M. R. Da releitura à escritura: um estudo da leitura pelo viés da pontuação. 340f. Tese (Doutorado em Letras) - Programa de Pós-Graduação em Letras, Universidade Federal do Rio Grande do Sul, Porto Alegre, 2002.

ORLANDI, E. P. Discurso e textualidade. 2. ed. Campinas: Pontes Editores, 2010.

ORLANDI, E. P. Análise de Discurso: princípios e procedimentos. (1999) 10. ed. Campinas: Pontes Editores, 2012a.

ORLANDI, E. P. Discurso em análise: Sujeito, sentido e ideologia. 2. ed. Campinas: Pontes Editores, 2012b.

PÊCHEUX, M. _ _ O discurso: estrutura ou acontecimento. Trad. Eni P. Orlandi. 4. Ed. Campinas: Pontes Editores, 2008.

PÊCHEUX, M. (1988) Semântica e discurso: uma crítica à afirmação do óbvio. Trad. Eni P. Orlandi et al. 4. ed. Campinas: Ed. da UNICAMP, 2009.

PÊCHEUX, M. Análise Automática do Discurso (AAD-69). In: GADET, Françoise \& HAK, Tony. Por uma Análise Automática do Discurso: Uma introdução à Obra d Michel Pêcheux. Campinas: Editora da Unicamp, 2014. p. 59-158.

PÊCHEUX, M. A análise de discurso: três épocas. In: GADET, Françoise \& HAK, Tony. Por uma Análise Automática do Discurso: Uma introdução à Obra d Michel Pêcheux. Campinas: Editora da Unicamp, 2014. p. 307-315.

RECUERO, R. Redes sociais na internet. Porto Alegre: Sulina, 2009. (Coleção Cibercultura).

RECUERO, R. A conversação como apropriação na comunicação mediada pelo computador. Disponível em: <http://www.raquelrecuero.com/raquelrecuerolivrocasper.pdf $>$ Acesso em: 15 ago. 2013.

SANT’ANNA, Denise Bernuzzi (org.). Políticas do corpo. São Paulo: Estação Liberdade, 1995. 